Cochrane Database of Systematic Reviews

\title{
EEG for children with complex febrile seizures (Review)
}

Shah PB, James S, Elayaraja S

Shah PB, James S, Elayaraja S.

EEG for children with complex febrile seizures.

Cochrane Database of Systematic Reviews 2017, Issue 10. Art. No.: CD009196.

DOI: 10.1002/14651858.CD009196.pub4.

www.cochranelibrary.com 
TABLE OF CONTENTS

HEADER 1

ABSTRACT

PLAIN LANGUAGE SUMMARY

BACKGROUND

OBJECTIVES

METHODS

RESULTS

DISCUSSION

AUTHORS' CONCLUSIONS

ACKNOWLEDGEMENTS

REFERENCES

CHARACTERISTICS OF STUDIES

APPENDICES

WHAT'S NEW

HISTORY

CONTRIBUTIONS OF AUTHORS

DECLARATIONS OF INTEREST

SOURCES OF SUPPORT

DIFFERENCES BETWEEN PROTOCOL AND REVIEW

INDEX TERMS

1

2

3

3

3

6

6

6 
[Intervention Review]

\section{EEG for children with complex febrile seizures}

Pankaj B Shah¹, Saji James², S Elayaraja²

1Department of Community Medicine, Sri Ramachandra Medical College and Research Institute, Sri. Ramachandra University, Chennai, India. 2Department of Paediatric Medicine, Sri Ramachandra Medical College and Research Institute, Sri. Ramachandra University, Chennai, India

Contact address: Pankaj B Shah, Department of Community Medicine, Sri Ramachandra Medical College and Research Institute, Sri. Ramachandra University, Ramachandra Nagar, Porur, Chennai, Tamil Nadu, 600116, India. drpankajsshah@yahoo.co.in.

Editorial group: Cochrane Epilepsy Group.

Publication status and date: New search for studies and content updated (no change to conclusions), published in Issue 10, 2017.

Citation: Shah PB, James S, Elayaraja S. EEG for children with complex febrile seizures. Cochrane Database of Systematic Reviews 2017, Issue 10. Art. No.: CD009196. DOI: 10.1002/14651858.CD009196.pub4.

Copyright @ 2017 The Cochrane Collaboration. Published by John Wiley \& Sons, Ltd.

\section{A B S T R A C T}

\section{Background}

Febrile seizures can be classified as simple or complex. Complex febrile seizures are associated with fever that lasts longer than 15 minutes, occur more than once within 24 hours, and are confined to one side of the child's body. It is common in some countries for doctors to recommend an electroencephalograph (EEG) for children with complex febrile seizures. A limited evidence base is available to support the use of EEG and its timing after complex febrile seizures among children.

\section{Objectives}

To assess the use of EEG and its timing after complex febrile seizures in children younger than five years of age.

\section{Search methods}

For the latest update of this review, we searched the Cochrane Epilepsy Group Specialized Register (23 January 2017), the Cochrane Central Register of Controlled Trials (CENTRAL) via the Cochrane Register of Studies Online (CRSO, 23 January 2017), MEDLINE (Ovid, 23 January 2017), and ClinicalTrials.gov (23 January 2017). We applied no language restrictions.

\section{Selection criteria}

All randomised controlled trials (RCTs) that examined the utility of an EEG and its timing after complex febrile seizures in children.

\section{Data collection and analysis}

The review authors selected and retrieved the articles and independently assessed which articles should be included. Any disagreements were resolved by discussion and by consultation with the Cochrane Epilepsy Group. We applied standard methodological procedures expected by Cochrane.

\section{Main results}

Of 41 potentially eligible studies, no RCTs met the inclusion criteria.

\section{Authors' conclusions}

We found no RCTs as evidence to support or refute the use of EEG and its timing after complex febrile seizures among children. An RCT can be planned in such a way that participants are randomly assigned to the EEG group and to the non-EEG group with sufficient sample size. Since the last version of this review, we have found no new studies. 


\section{PLAIN LANGUAGE SUMMARY}

\section{EEG for children with complex febrile seizures}

\section{Background}

Febrile seizures (fits) can be classified as simple or complex. Complex febrile seizures are associated with a high temperature (fever), last longer than 15 minutes, occur more than once within 24 hours, and are confined to one side of the child's body. It is common in some countries for doctors to recommend an electroencephalograph (EEG), which records electrical activity in the brain, on children with complex febrile seizures. The EEG may help identify why the seizures occur and predict the risk of future seizures.

\section{Study characteristics}

We searched scientific databases for randomised controlled trials (clinical studies where people are randomly put into one of two or more treatment groups; these are regarded as a gold standard for trial design) that compared EEG with no EEG or a delayed EEG (occurring at second seizure) in children under five years of age with a first complex febrile seizure. We planned to look at the number of seizures that occurred at 1, 6, 12, and 24 months after EEG.

\section{Key results and quality of the evidence}

We attempted to search all possible sources but were unable to find any randomised controlled trials to address the issue up to 23 January 2017. We concluded that there is no high-quality evidence to support or refute the use of an EEG and its timing after complex febrile seizures in children. Well-designed randomised controlled trials are therefore required. We intend to update this review regularly with the hope that new randomised studies will be reported in the future. 


\section{B A C K G R O U N D}

\section{Description of the condition}

According to the US National Institutes of Health and the International League Against Epilepsy, febrile seizures can occur between the ages of one month and five years (Freeman 1980; ILAE 1993), and are associated with fever with no intracranial infection or defined cause (Freeman 1980). Febrile seizures can be classified as simple or complex. Simple febrile seizures are generalised tonic or tonic-clonic convulsions lasting less than 15 minutes that occur only once in a 24-hour period in a neurologically and developmentally normal child. If focal features are present, the seizures last longer than 15 minutes, the child has a preexisting neurological condition, and the seizures occur multiple times (recurrent within 24 hours) or within the same febrile event, the febrile seizures are referred to as complex (Francis 2006; Gordon 2001; Kliegman 1996; Waruiru 2004). The incidence of febrile seizures varies from $2 \%$ to $5 \%$ in Western Europe and the USA (Joshi 2005; Waruiru 2004), from $5 \%$ to $10 \%$ in India, and is reported to be $8.8 \%$ in Japan and $14 \%$ in Guam (Waruiru 2004). Data from low- to middle-income countries are limited (Waruiru 2004).

A child with febrile seizures usually does not need to be hospitalised. However, when the seizure is prolonged or is accompanied by a serious infection, or when the source of the infection cannot be determined, hospitalisation for observation may be recommended. Prolonged daily use of oral antiepileptic drugs to prevent febrile seizures is usually not recommended because of their potential for adverse effects and their questionable effectiveness in preventing such seizures (Kliegman 1996; Offringa 2012).

\section{Description of the intervention}

An electroencephalograph (EEG) records brain waves detected by electrodes placed on the scalp. Reporting of paroxysmal EEG abnormalities in children with febrile seizures may vary widely (Panayiotopoulos 2005). The reasons may be related to differences in participant selection by different authors, the criteria used in different studies to define paroxysmal discharges, or the timing of the EEG.

The American Academy of Pediatrics practice parameter on febrile seizures recommends that an EEG should not be part of a routine investigation after a simple febrile seizure in neurologically normal children because of its lack of usefulness in predicting recurrence risk or future epilepsy (American Academy of Pediatrics 1996; Joshi 2005; Kuturec 1997). The quality standards subcommittees of the American Academy of Neurology, the Child Neurology Society, and the American Epilepsy Society recommend an EEG in the initial evaluation of the first afebrile seizure, as an abnormal EEG predicts recurrence (Hirtz 2000; Joshi 2005). The precise role of EEG in the evaluation of children with complex febrile seizure has not been established; however, it is common for both paediatricians and specialists to recommend EEGs on these children in some countries (Joshi 2005; Millichap 1991). An EEG taken within the first week after a febrile seizure is termed an 'early EEG', whereas an EEG taken anytime between the first week and one month after the seizure activity is termed a 'late EEG'. Few retrospective studies have attempted to assess the use of EEGs in complex febrile seizure (Maytal 2000; Yucel 2004).

\section{How the intervention might work}

An EEG performed in the evaluation of complex febrile seizures may help identify the nature of the underlying acute or remote cerebral pathology and predict the risk of future seizures.

\section{Why it is important to do this review}

Much uncertainty remains about the use of an EEG and its timing in children with complex febrile seizures, hence the need to carry out this review. This is an update of a previously published review in the Cochrane Database of Systematic Reviews published in 2014 and first update published in 2015, which found no evidence to support or refute the use of EEG for children with complex febrile seizures.

\section{O B J E C T IVES}

To assess the use of EEG and its timing after complex febrile seizures in children younger than five years of age.

\section{METHODS}

\section{Criteria for considering studies for this review Types of studies}

We planned to include parallel-group randomised controlled trials (RCTs).

\section{Types of participants}

Participants in the studies eligible for inclusion were children of either sex younger than five years of age with a first episode of complex febrile seizure.

We would include children in the review only:

- if the EEG was performed after the first complex febrile seizure episode; or

- if recruitment of children into the study was delayed and the EEG was performed before the child's second seizure.

We excluded studies in which children had other neurological disorders (e.g. behavioural disorders, cerebral palsy, mental retardation).

\section{Types of interventions}

The intervention was EEG investigation. We selected two comparisons.

- Children without administration of an EEG versus children with administration of an EEG (early or late or at any time).

- Children with administration of an early EEG versus children with administration of a late EEG.

\section{Types of outcome measures}

\section{Primary outcomes}

1. Proportions of children developing seizures of any type after follow-up periods of one month, six months, 12 months, and two years in two comparison groups of EEG versus no EEG and early EEG versus late EEG. We decided to include any type of seizure in this outcome. We recorded the available outcome measures with respect to a particular time period. In addition, we planned to contact the original trial authors to enquire whether outcome 
measurements had been recorded for other time periods of interest. We believe that the most important clinically relevant time period was two years.

2. Risk of recurrence between no EEG and EEG (early EEG, late EEG, or any other time), which will act as a surrogate outcome.

3. Total number of seizure episodes in each group during two-year follow-up.

4. Time to development of seizures as time-to-event outcome.

5. Adverse events (although the EEG may not cause any adverse event per se, adverse events may be related to sedation given to children and may be transient).

\section{Search methods for identification of studies}

\section{Electronic searches}

We ran searches for the original review on 18 October 2012, and ran subsequent searches on 17 October 2013, 6 July 2015, and 23 January 2017. For the latest update, we searched the following databases using the search strategies shown in Appendix 1.

- Cochrane Epilepsy Group Specialized Register (23 January 2017).

- Cochrane Central Register of Controlled Trials (CENTRAL) via the Cochrane Register of Studies Online (CRSO, 23 January 2017).

- MEDLINE (Ovid, 1946 to 23 January 2017).

- US National Institutes of Health Ongoing Trials Register ClinicalTrials.gov (clinicaltrials.gov/) (23 January 2017).

\section{Searching other resources}

We searched the references of all studies retrieved in full to identify additional research papers. We contacted authors of relevant articles and experts in the field to ask about additional research papers and unpublished trials. We looked for conference proceedings for trials relevant to our review. We decided not to impose language restrictions.

\section{Data collection and analysis}

\section{Selection of studies}

Two review authors (PBS (methodology expert), SJ (content expert)) conducted the searches and independently carried out an initial screening of the titles of research papers (Lefebvre 2011). The review authors independently screened the abstracts of papers deemed potentially relevant. We retrieved the full text for all articles whose abstracts were relevant. When full-text articles were not available, we contacted the study authors and asked them to provide the full text of the article. We decided to use this search methodology during screening of the cross-references of the full-text retrieved articles and articles suggested by authors and experts in the field. Two review authors (PBS, SJ) independently reviewed the full-text articles and classified each into one of the following groups: included studies; excluded studies; or studies pending decision (if required, we contacted study authors to request additional details of the study).

We recorded the information on the eligibility assessment form included in Appendix 2.

We attempted to identify duplicate publications by assessing similar study types, same place, or same authors (maybe with different sequence). We used reference management software
(Mozilla with Zotero) to identify and exclude duplicate publications. In cases of doubt, we contacted the study authors to avoid inclusion of duplicate publications in this review.

We agreed to resolve any disagreements by discussion and to reach a final decision by consensus or by consultation with the Cochrane Epilepsy Group. We used standard methodological procedures expected by Cochrane.

\section{Data extraction and management}

We could not extract the data in the present review, as no study met the inclusion criteria. We planned to conduct the data extraction process as follows.

Two review authors (PBS, SJ) planned to independently extract required data from the full-text articles of the included studies. (We have included the data extraction form in Appendix 3.) The data extraction form has the following five components.

- Identification of study.

- Characteristics of included studies with a brief description in tabular form of methods, participants, interventions and outcomes, and notes on specific issues (if any).

- 'Risk of bias' table, as per guidelines of the Cochrane Handbook for Systematic Reviews of Interventions (Altman 2011).

- Measurements of treatment effects extracted.

- Information pertaining to any discrepancy noted in records of the clinical trial registry.

We agreed to resolve any disagreements by discussion and to reach a final decision by consensus or by consultation with the Cochrane Epilepsy Group. We agreed to follow the guidelines of the Quality of Reporting of Meta-Analyses (QUOROM) statement, and PRISMA (formerly QUOROM) (Moher 2009).

We have provided a list of excluded studies with reasons for exclusion in tabular form (see Characteristics of excluded studies table).

We planned to report in tabular form the details of any ongoing studies in terms of methods, interventions and outcomes, or trial registration numbers; however, we found no ongoing studies.

\section{Assessment of risk of bias in included studies}

We could not assess the risk of bias in the present review, as no study met the inclusion criteria.

We planned to report risk of bias as recommended in the Cochrane Handbook for Systematic Reviews of Interventions for 'Risk of bias' tables (Appendix 4) (Altman 2011). We planned to fill the description for each domain with a quote from the article or correspondence and then comment with judgement regarding particular bias (yes, no, or unclear). We would undertake a summary assessment of risk of bias for each outcome (across domains) within and across studies and to make judgements about the risk of bias as low, unclear, or high. We planned to report a 'Risk of bias' graph and a 'Risk of bias' summary figure. Two review authors (PBS, SJ) intended to independently assess the risk of bias. Any disagreements would have been resolved by discussion and through consensus or by consultation with the Cochrane Epilepsy Group. 


\section{Measures of treatment effect}

We could not measure the treatment effect in the present review, as no study met the inclusion criteria. We planned to measure treatment effect as follows.

We planned to calculate the proportions of children developing seizures after follow-up periods of one month, six months, 12 months, and two years. We also planned to calculate risk of recurrence between no EEG and EEG (early EEG, late EEG, or any other time), total number of seizure episodes in each group during the two-year follow-up, time to development of seizures as timeto-event outcome, and adverse events (if any). We planned to use odds ratio for dichotomous outcomes and mean difference for continuous data. For data provided in other forms, we decided to convert extracted data to the above measures. We planned to extract or calculate $95 \%$ confidence intervals for all data. In the case of insufficient information, we would contact study authors to ask for additional details.

\section{Unit of analysis issues}

We did not anticipate any unit of analysis issues.

\section{Dealing with missing data}

We contacted study authors to ask for missing data such as method of randomisation if not stated in the paper or whether an outcome of interest that was not reported had been analysed. The reasons for missing data would have been useful in the imputation of missing data.

\section{Assessment of heterogeneity}

We could not assess the heterogeneity in the present review, as no study met the inclusion criteria. We planned to assess heterogeneity as follows.

We planned to assess clinical heterogeneity by comparing participant factors, interventional factors, outcome factors, and methodological heterogeneity by study methods. We also planned to assess statistical heterogeneity by measuring variability in interventional effects by visually comparing the overlap of confidence intervals on forest plots. If confidence intervals for the results of individual studies have poor overlap, this might indicate the presence of statistical heterogeneity. We also planned to measure statistical heterogeneity using the $\mathrm{I}^{2}$ statistic, interpreting it as follows (Deeks 2011).

- $0 \%$ to $40 \%$ : might not be important.

- $30 \%$ to $60 \%$ : may represent moderate heterogeneity.

- $50 \%$ to $90 \%$ : may represent substantial heterogeneity.

- $75 \%$ to $100 \%$ : considerable heterogeneity.

\section{Assessment of reporting biases}

We planned during this stage to determine primary and secondary outcomes of the included studies from clinical trial registries (if possible) to assess any discrepancies in reporting, which we would have reported had we found any. We planned to assess funnel plot asymmetry if we identified more than 10 studies. Reasons for asymmetry include publication bias, outcome reporting bias, and heterogeneity.

\section{Data synthesis}

We did not attempt data synthesis in the present review, as no study met the inclusion criteria. We planned to perform data synthesis as follows.

We planned to analyse each trial and record data on the data extraction form. The review authors would independently enter the results of each study using Review Manager 5 (RevMan 2014). We planned to carry out a meta-analysis according to Cochrane guidelines (Higgins 2011); the most common method available using Review Manager 5 is the Mantel-Haenszel method. If RCTs were clustered, we would have used the inverse method. In case of heterogeneity, we planned to carry out a thorough assessment (see Assessment of heterogeneity).

\section{Subgroup analysis and investigation of heterogeneity}

We did not attempt subgroup analysis and investigation of heterogeneity in the present review, as no study met the inclusion criteria. We agreed upon the following process.

We planned to carry out subgroup analyses based on sex, duration of disease, duration of hospitalisation, and length of follow-up. In cases of significant heterogeneity, we might have followed the steps outlined below.

- Recheck extraction and recording of data.

- Change from random-effects to fixed-effect model.

- Perform sensitivity analysis (see Sensitivity analysis).

- Explore heterogeneity by subgroup analysis.

- Present systematic review without meta-analysis.

\section{Sensitivity analysis}

Sensitivity analysis is a repeat primary analysis in which alternative decisions and ranges of values are substituted for decision making related to assessment of the robustness of conclusions.

We did not attempt sensitivity analysis in the present review, as no study met the inclusion criteria.

We planned to carry out the following steps in a sensitivity analysis.

- Some studies have larger effects than others because random error means that multiple replications of the same study will produce different effect estimates due to sampling variation, even if replications would yield the right answer on average. The results of smaller studies are subject to greater sampling variation and hence are less precise. Imprecision is reflected in the confidence interval around the intervention effect estimate from each study and in the weight given to the results of each study in a meta-analysis. More precise results are given more weight.

- In cases of missing values, use of the following imputation methods, of which many methods for imputation techniques have been proposed, is suggested. In cases of dichotomous data, best case-worst case analysis is performed to find out how the risk factor or the result value may vary in different situations. For continuous data, the last value takes the role of the missing value. These imputations are important because RCTs have to be analysed as intention-to-treat analyses.

- Use random-effects rather than fixed-effect model. 
While the above sensitivity analyses were prespecified, it was not possible to specify all sensitivity analyses, as issues may develop only in the course of completing the review. Where sensitivity analysis influenced the robustness of our conclusion, we planned to attempt to resolve the uncertainty by contacting trial authors and consulting the Cochrane Epilepsy Group. As it might not have been possible to report all sensitivity analyses in detail, we planned to provide a summary table. Sensitivity analysis would have helped us to explore the influence of various factors.

\section{'Summary of findings' tables}

We planned to provide 'Summary of findings' tables, prepared using GRADEpro software (GRADEpro 2014). We planned to report a rating of overall quality of evidence for each outcome, as well as conclusions, and implications for practice and research (Appendix 5). Two review authors (PBS, SJ) would independently prepare the 'Summary of findings' tables. Any disagreements would have been resolved by discussion and through consensus or by consultation with the Cochrane Epilepsy Group.

\section{R E S U L T S}

\section{Description of studies}

\section{Results of the search}

With the help of the Information Specialist of the Cochrane Epilepsy Group, our searches identified 41 potentially eligible studies. A summary of the search results is shown in Appendix 6. Literature searches identified four studies in this update. After assessing the titles and abstracts, we excluded all 41 studies; therefore, no studies were eligible for inclusion in the review (see Characteristics of excluded studies table).

\section{Included studies}

None of the studies met the inclusion criteria, thus no studies were included in the present review.

\section{Excluded studies}

We excluded all 41 studies because the study design and the intervention were not of interest to this review (see Excluded studies; Characteristics of excluded studies table).

\section{Risk of bias in included studies}

We included no studies in this review, hence risk of bias is not applicable.

\section{Effects of interventions}

In the absence of any suitable studies for this review, analyses were not possible. Although we could not attempt data collection and analysis as specified in the protocol, we decided to describe the process of different aspects of data collection and analysis, as the review will be updated regularly and the full protocol may not be easily accessible to all users of this evidence.

We could not provide 'Summary of findings' table in the present review, as no study met the inclusion criteria.

\section{DISCUSSION}

\section{Summary of main results}

We did not find any RCTs of EEG for children with complex febrile seizures. Hence, there is currently no randomised high-quality evidence to report for an EEG and its timing after complex febrile seizures in children younger than five years of age.

\section{Overall completeness and applicability of evidence}

We performed a comprehensive search of the literature as described in Appendix 6, and assessed 41 studies that may have been relevant to the review. We excluded all 41 studies, so we identified no RCTs.

\section{Quality of the evidence}

We found no studies.

\section{Potential biases in the review process}

None.

\section{Agreements and disagreements with other studies or reviews}

We found no other similar review. However, a few published nonrandomised studies to date have looked specifically at complex febrile seizures and the role of EEG in their evaluation (Joshi 2005; Maytal 2000; Yucel 2004). In one retrospective review of 33 neurologically normal children with EEGs within one week of complex febrile seizures, Maytal and colleagues found no children with abnormalities, but Yucel and colleagues reported abnormalities in 71 of 159 children with complex febrile seizures analysed retrospectively over seven years. In Yucel 2004, 16 children had abnormal EEG records in the first week. Of the 71 children with abnormal EEG records, 51 were diagnosed with epilepsy on followup. One other study by Joshi and colleagues showed that children with complex febrile seizures are approximately 3.5 times more likely to display an abnormal EEG within seven days post ictus in comparison with children with complex febrile seizures in whom the EEG was performed beyond the seven-day period post ictus. Hence, conflicting reports describe the utility of EEG and its timing after complex febrile seizures among children.

\section{AUTHORS' CONCLUSIONS}

\section{Implications for practice}

Although it is common for both paediatricians and specialists in some countries to recommend electroencephalographs (EEG) for children with complex febrile seizures (Joshi 2005; Millichap 1991), evidence to support or refute the use of EEG and its timing after complex febrile seizures among children is lacking. We have found no new studies since the last version of this review.

\section{Implications for research}

This review highlighted the absence of randomised controlled trials (RCTs) investigating the utility of EEG and its timing after complex febrile seizures in children. We found no RCT evidence to support or refute the utility of EEG and its timing after complex febrile seizures in children. A randomised controlled trial can be planned in such a way that participants are randomly assigned to an EEG group and a non-EEG group with sufficient sample size. Hence, well- 
designed RCTs are required to confirm or refute the utility of EEG. These clinical trials should follow good clinical practice guidelines with an emphasis on methodological issues such as randomisation, blinding of outcome assessment, intention-to-treat analysis, and scientific means to reduce bias.

Updating the review: in accordance with Cochrane policy, we plan to update this review every two years (or sooner, should we find any important study that fulfils the inclusion criteria).

\section{ACKNOWLEDGEMENTS}

We would like to thank the following.

- The Cochrane Epilepsy Group for providing valuable guidance.
- The Indian Council of Medical Research (ICMR) and the South Asian Cochrane Network and Centre, Prof BV Moses and the ICMR Centre for Advanced Research and Training in EvidenceBased Healthcare and CMC Vellore for supporting the training programme and making the Cochrane Library free for India.

- Prof Prathap Tharyan, Director, South Asian Cochrane Network and Centre, Prof BV Moses and the ICMR Centre for Advanced Research and Training in Evidence-Based Healthcare and CMC Vellore for guidance provided during the training workshop.

- Management, Vice Chancellor, Deans, Heads of Departments, and Faculty members of our departments of Sri. Ramachandra University for continuous inspiration and support.

- Family members for continuous inspiration and support. 


\section{RE F E R E N C E S}

\section{References to studies excluded from this review}

\section{Aksu 2011 \{published data only\}}

Aksu R, Kumandas S, Akin A, Bicer C, Gumus H, Guler G, et al. The comparison of the effects of dexmedetomidine and midazolam sedation on electroencephalography in pediatric patients with febrile convulsion. Paediatric Anaesthesia 2011;21(4):373-8.

\section{Berg 2008 \{published data only\}}

Berg AT. Risk of recurrence after a first unprovoked seizure. Epilepsia 2008;49(Suppl 1):13-8.

\section{Bernasconi 1998 \{published data only\}}

Bernasconi A, Andermann F, Cendes F, Dubeau F, Andermann E, Olivier A. Nocturnal temporal lobe epilepsy. Neurology 1998;50(6):1772-7.

\section{Burneo 2005 \{published data only\}}

Burneo JG, Knowlton RC, Martin R, Faught RE, Kuzniecky RI. Race/ethnicity: a predictor of temporal lobe epilepsy surgery outcome?. Epilepsy \& Behavior 2005;7(3):486-90.

\section{Conry 2014 \{published data only\}}

Conry J, Ng YT, Peng G, Lee D, Isojarvi J. Efficacy and safety of clobazam for lgs patients who completed all 15 weeks of the phase iii contain trial. Epilepsy Currents 2014;14:390.

\section{Drayer 1982 \{published data only\}}

Drayer B, Suslavich F, Luther J, Rommel A, Allen S, Dubois P, et al. Clinical trial of iopamidol for lumbosacral myelography. Electroencephalography 1982;3(1):59-64.

\section{Fallah 2007 \{published data only\}}

Fallah R, Gofrani M. Comparison of intravenous lidocaine and midazolam infusion for refractory convulsive status epilepticus in children. Journal of Pediatric Neurology 2007;5(4):287-90.

\section{Ghazavi 2016 \{published data only\}}

Ghazavi A, Abbasi E, Nikibakhsh A, Sadeghi E, Sadeghimanesh J. Comparison of prophylactic effect of clobazam and diazepam in children with simple febrile convulsion (SFC). International Journal of Tropical Medicine 2016;11(2):21-3.

\section{Gradisnik 2015 \{published data only\}}

Gradisnik P, Zagradisnik B, Palfy M, Kokalj-Vokac N, MarcunVarda N. Predictive value of paroxysmal EEG abnormalities for future epilepsy in focal febrile seizures. Brain and Development 2015;37(9):868-73. [DOI: 10.1016/j.braindev.2015.02.005]

\section{Grahn 2013 \{published data only\}}

Grahn A, Hagberg L, Nilsson S, Blennow K, Zetterberg H, Studahl M. Cerebrospinal fluid biomarkers in patients with varicella-zoster virus CNS infections. Journal of Neurology 2013;260(7):1813-21.
Grigsby 1998 \{published data only\}

Grigsby J, Kramer RE, Schneiders JL, Gates JR, Brewster SW. Predicting outcome of anterior temporal lobectomy using simulated neural networks. Epilepsia 1998;39(1):61-6.

\section{Gumus 2015 \{published data only\}}

Gumus H, Bayram AK, Poyrazoglu HG, Canpolat DG, Per H, Canpolat $\mathrm{M}$, et al. Comparison of effects of different dexmedetomidine and chloral hydrate doses used in sedation on electroencephalography in pediatric patients. Journal of Child Neurology 2015;30(8):983-8. [DOI: 10.1177/0883073814549582]

\section{Heijbel 1980 \{published data only\}}

Heijbel J, Blom S, Bergfors PG. Simple febrile convulsions. A prospective incidence study and an evaluation of investigations initially needed. Neuropadiatrie 1980;11(1):45-56.

\section{Huang 2007 \{published data only\}}

Huang Y, Yang L, Wang S, Wang G. Alterative application of five anticonvulsants according to the half life for the treatment of status epilepticus in children with severe viral encephalitis. Neural Regeneration Research 2007;2(9):561-4.

\section{Kaminska 1999 \{published data only\}}

Kaminska A, Ickowicz A, Plouin P, Bru MF, Dellatolas G, Dulac O. Delineation of cryptogenic Lennox-Gastaut syndrome and myoclonic astatic epilepsy using multiple correspondence analysis. Epilepsy Research 1999;36(1):15-29.

Knudsen 1985 \{published data only\}

Knudsen FU. Effective short term diazepam prophylaxis in febrile convulsions. Journal of Pediatrics 1985;106(3):487-90.

Mackintosh 1970 \{published data only\}

Mackintosh TF. Studies on prophylactic treatment of febrile convulsions in children. Is it feasible to inhibit attacks by giving drugs at the first sign of fever or infection?. Clinical Pediatrics 1970;9(5):283-6.

\section{Mahmoudian 2004 \{published data only\}}

Mahmoudian T, Zadeh MM. Comparison of intranasal midazolam with intravenous diazepam for treating acute seizures in children. Epilepsy \& Behavior 2004;5(2):253-5.

Mamelle 1982 \{published data only\}

Mamelle JC, Mamelle N, Plasse JC, Revol M, Gilly R. The efficacy of sodium valproate compared with that of phenobarbitone and placebo in the prophylaxis of febrile convulsions. Pediatrics 1982;37(6):433-45

Mamelle 1984 \{published data only\}

Mamelle N, Mamelle JC, Plasse JC, Revol M, Gilly R. Prevention of recurrent febrile convulsions: a randomized therapeutic assay: sodium valproate, phenobarbital and placebo. Neuropediatrics 1984;15(1):37-42. 
Natriashvili 2005 \{published data only\}

Natriashvili G, Natriashvili S, Kapanadze N. Mexidol in treatment of children with generalized epilepsy and febrile seizures.

Georgian Medical News 2005;122:40-4.

\section{NCT01370044 \{published data only\}}

NCT01370044. Carbon dioxide (Carbogen) for the treatment of febrile seizures (CARDIF). clinicaltrials.gov/show/NCT01370044 (first received 17 October 2013).

NCT01694524 \{published data only\}

NCT01694524. Nervous system infections among patients with febrile seizure. clinicaltrials.gov/show/NCT01694524 (first received17 October 2013).

\section{NCT01738841 \{published data only\}}

NCT01738841. Safety study of measles-mumps-rubellavaricella (MMRV) vaccine, Priorix-Tetra ${ }^{\mathrm{TM}}$ in children living in the Philippines. clinicaltrials.gov/show/NCT01738841 (first received17 October 2013).

\section{NCT01884766 \{published data only\}}

NCT01884766. Copeptin in childhood epilepsy. clinicaltrials.gov/show/NCT01884766 (first received17 October 2013).

\section{NCT01906619 \{published data only\}}

NCT01906619. Respiratory physiology in children with febrile seizures. clinicaltrials.gov/show/NCT01906619 (first received 17 October 2013).

\section{NCT01931813 \{published data only\}}

NCT01931813. METHORIVAC - vaccinal pharmacoepidemiologic. clinicaltrials.gov/show/NCT01931813 (first received 17 October 2013).

\section{NCT01946594 \{published data only\}}

NCT01946594. Clinical Immunization Safety Assessment (CISA) project: pilot study to assess the effect of prophylactic antipyretics on immune responses and fever after IIV. clinicaltrials.gov/show/NCT01946594 (first received 17 October 2013).

\section{NCT02374450 \{published data only\}}

NCT02374450. A surveillance study of diseases specified as adverse events of specific interest (AESI) and serious adverse events (SAEs) in children in Africa prior to implementation of the RTS,S/AS01E candidate vaccine. clinicaltrials.gov/show/ NCT02374450 (first received6 July 2015).

\section{Novotny 2010 \{published data only\}}

Novotny E, Renfroe B, Yardi N, Nordli D, Ness S, Wang S, et al. Randomized trial of adjunctive topiramate therapy in infants with refractory partial seizures. Neurology 2010;74(9):714-20.

\section{O'Brien 2008 \{published data only\}}

O'Brien TJ, Mosewich RK, Britton JW, Cascino GD, So EL. History and seizure semiology in distinguishing frontal lobe seizures and temporal lobe seizures. Epilepsy Research 2008;82(2-3):177-82

\section{Pavlidou 2006 \{published data only\}}

Pavlidou E, Tzitiridou M, Panteliadis C. Effectiveness of intermittent diazepam prophylaxis in febrile seizures: longterm prospective controlled study. Journal of Child Neurology 2006;21(12):1036-40.

Pina-Garza 2005 \{published data only\}

Pina-Garza JE, Espinoza R, Nordli D, Bennett DA, Spirito S, Stites TE, et al. Oxcarbazepine adjunctive therapy in infants and young children with partial seizures. Neurology 2005;65(9):1370-5

\section{Reijs 2007 \{published data only\}}

Reijs RP, van Mil SG, Arends JB, van HMH, Weber JW, Renier WO, et al. Cryptogenic localization related epilepsy in children from a tertiary outpatient clinic: is neurological and neuropsychological outcome predictable?. Clinical Neurology and Neurosurgery 2007;109(5):422-30.

\section{Rosati 2003 \{published data only\}}

Rosati A, Aghakhani Y, Bernasconi A, Olivier A, Andermann F, Gotman J, et al. Intractable temporal lobe epilepsy with rare spikes is less severe than with frequent spikes. Neurology 2003;60(8):1290-5.

\section{Rose 2005 \{published data only\}}

Rose W, Kirubakaran C, Scott JX. Intermittent clobazam therapy in febrile seizures. Indian Journal of Pediatrics 2005;72(1):31-3.

Rosenfeld 2014 \{published data only\}

Rosenfeld W, Isojarvi J, Nichol K, Lee D. Response to clobazam among benzodiazepine experienced lgs patients during the CONTAIN trial. Epilepsy Currents 2014;14:390-1.

Rosman 1987 \{published data only\}

Rosman NP. Febrile seizures. Emergency Medicine Clinics of North America 1987;5(4):719-37.

Strengell 2009 \{published data only\}

Strengell T, Uhari M, Tarkka R, Uusimaa J, Alen R, Lautala P, et al. Antipyretic agents for preventing recurrences of febrile seizures: randomized controlled trial. Archives of Pediatrics and Adolescent Medicine 2009;163(9):799-804.

Tsuboi 1988 \{published data only\} Tsuboi T. Prevalence and incidence of epilepsy in Tokyo. Epilepsia 1988;29(2):103-10.

Vecchi 2016 \{published data only\} Vecchi M, Barba C, De Carlo D, Stivala M, Guerrini R, Albamonte $\mathrm{E}$, et al. Symptomatic and presumed symptomatic focal epilepsies in childhood: an observational, prospective multicentre study. Epilepsia 2016;57(11):1808-16. [DOI: 10.1111/ epi.13574]

\section{Additional references}

\section{Altman 2011}

Higgins JPT, Altman DG. Chapter 8: Assessing risk of bias in included studies. In: Higgins JPT, Green S (editors). Cochrane 
Handbook for Systematic Reviews of Interventions Version 5.1.0 [updated March 2011]. The Cochrane Collaboration, 2011. Available from handbook.cochrane.org.

\section{American Academy of Pediatrics 1996}

American Academy of Pediatrics. Practice parameter: the neurodiagnostic evaluation of the child with a first simple febrile seizure. American Academy of Pediatrics. Provisional Committee on Quality Improvement, Subcommittee on Febrile Seizures. Pediatrics 1996;97:769-72.

\section{Deeks 2011}

Deeks JJ, Higgins JPT, Altman DG. Chapter 9: Analysing data and undertaking meta-analyses. In: Higgins JPT, Green S (editors). Cochrane Handbook for Systematic Reviews of Interventions Version 5.1.0 [updated March 2011]. The Cochrane Collaboration, 2011. Available from handbook.cochrane.org.

\section{Francis 2006}

Francis J, DiMario MD Jr. Children presenting with complex febrile seizures do not routinely need computed tomography scanning in the emergency department. Pediatrics 2006;117(2):528-30.

\section{Freeman 1980}

Freeman JM. Febrile seizures: a consensus of their significance, evaluation, and treatment. Pediatrics 1980;66:1009-12. [PUBMED: 7454463]

\section{Gordon 2001}

Gordon KE, Dooley JM, Camfield PR, Camfield CS, MacSween J. Treatment of febrile seizures: the influence of treatment efficacy and side-effect profile on value to parents. Pediatrics 2001;108(5):1080-8.

\section{GRADEpro 2014 [Computer program]}

McMaster University (developed by Evidence Prime), available at gradepro.org. GRADEpro. Hamilton (ON): McMaster University (developed by Evidence Prime), available at gradepro.org, 2014.

\section{Higgins 2011}

Higgins JPT, Green S (editors). Cochrane Handbook for Systematic Reviews of Interventions Version 5.1.0 [updated March 2011]. The Cochrane Collaboration, 2011. Available from handbook.cochrane.org.

\section{Hirtz 2000}

Hirtz D, Ashwal S, Berg A, Bettis D, Camfield C, Camfield P, et al. Practice parameter: evaluating a first nonfebrile seizure in children: report of the quality standards subcommittee of the American Academy of Neurology, the Child Neurology Society, and the American Epilepsy Society. Neurology 2000;55:616-23.

\section{ILAE 1993}

International League Against Epilepsy. Guidelines for epidemiologic studies on epilepsy. Epilepsia 1993;34:592-6.

\section{Joshi 2005}

Joshi C, Wawrykow T, Patrick J, Prasad A. Do clinical variables predict an abnormal EEG in patients with complex febrile seizures?. Seizure 2005;14(6):429-34.

\section{Kliegman 1996}

Kliegman R. Seizures. Nelson Essentials of Pediatrics. 5th Edition. Philadelphia: Saunders, 1996:833-5; 838.

\section{Kuturec 1997}

Kuturec M, Emoto SE, Sofijanov N, Dukovski M, Duma F, Ellenberg JH, et al. Febrile seizures: is the EEG a useful predictor of recurrences?. Clinical Pediatrics 1997;36(1):31-6. [PUBMED: 9007345]

\section{Lefebvre 2011}

Lefebvre C, Manheimer E, Glanville J. Chapter 6: Searching for studies. In: Higgins JPT, Green S (editors). Cochrane Handbook for Systematic Reviews of Interventions Version 5.1.0 [updated March 2011]. The Cochrane Collaboration, 2011. Available from handbook.cochrane.org.

\section{Maytal 2000}

Maytal J, Steel R, Eviatar L, Novak G. The value of early postictal EEG in children with complex febrile seizures. Epilepsia 2000;41:219-21.

\section{Millichap 1991}

Millichap JG. Management of febrile seizures: current concepts and recommendations for phenobarbital and the electroencephalogram. Clinical Electroencephalography 1991;22(1):5-12.

\section{Moher 2009}

Moher D, Liberati A, Tetzlaff J, Altman DG, PRISMA Group. Preferred reporting items for systematic reviews and metaanalyses: the PRISMA statement. BMJ 2009;339:b2535.

\section{Mozilla with Zotero [Computer program]}

Roy Rosenzweig Center for History and New Media, available at https://www.zotero.org/download/. Mozilla with Zotero. Roy Rosenzweig Center for History and New Media, available at https://www.zotero.org/download/, 2009.

\section{Offringa 2012}

Offringa M, Newton R. Prophylactic drug management for febrile seizures in children. Cochrane Database of Systematic Reviews 2012, Issue 4. [DOI: 10.1002/14651858.CD003031.pub2]

\section{Panayiotopoulos 2005}

Panayiotopoulos CP. Chapter 2: Optimal use of the EEG in the diagnosis and management of epilepsies. The Epilepsies: Seizures, Syndromes and Management. Chipping Norton, UK: Bladon Medical Publishing, 2005.

\section{RevMan 2014 [Computer program]}

The Nordic Cochrane Centre, The Cochrane Collaboration. Review Manager (RevMan). Version 5.3. Copenhagen: The Nordic Cochrane Centre, The Cochrane Collaboration, 2014.

\section{Waruiru 2004}

Waruiru C. Febrile seizures: an update. Archives of Disease in Childhood 2004;89:751-6. 


\section{Yucel 2004}

Yucel O, Aka S, Yazicioglu L, Ceran O. Role of early EEG and neuroimaging in determination of prognosis in children with complex febrile seizure. Pediatrics International 2004;46:463-7.

\section{References to other published versions of this review \\ Shah 2011}

Shah PB, James S, Elayaraja S. EEG for children with complex febrile seizures. Cochrane Database of Systematic Reviews 2011, Issue 7. [DOI: 10.1002/14651858.CD009196]

\section{CHARACTERISTICS OF STUDIES}

Characteristics of excluded studies [ordered by study ID]

\section{Shah 2014}

Shah PB, James S, Elayaraja S. EEG for children with complex febrile seizures. Cochrane Database of Systematic Reviews 2014, Issue 1. [DOI: 10.1002/14651858.CD009196.pub2]

\section{Shah 2015}

Shah PB, James S, Elayaraja S. EEG for children with complex febrile seizures. Cochrane Database of Systematic Reviews 2015, Issue 12. [DOI: 10.1002/14651858.CD009196.pub3]

\begin{tabular}{|c|c|}
\hline Study & Reason for exclusion \\
\hline Aksu 2011 & Study did not make a comparison between EEG and no EEG or early EEG and late EEG. \\
\hline Berg 2008 & Study did not make a comparison between EEG and no EEG or early EEG and late EEG. \\
\hline Bernasconi 1998 & Study did not make a comparison between EEG and no EEG or early EEG and late EEG. \\
\hline Burneo 2005 & Study did not make a comparison between EEG and no EEG or early EEG and late EEG. \\
\hline Conry 2014 & Study did not make a comparison between EEG and no EEG or early EEG and late EEG. \\
\hline Drayer 1982 & Study did not make a comparison between EEG and no EEG or early EEG and late EEG. \\
\hline Fallah 2007 & Study did not make a comparison between EEG and no EEG or early EEG and late EEG. \\
\hline Ghazavi 2016 & Study did not make a comparison between EEG and no EEG or early EEG and late EEG. \\
\hline Gradisnik 2015 & Study did not make a comparison between EEG and no EEG or early EEG and late EEG. \\
\hline Grahn 2013 & Study did not make a comparison between EEG and no EEG or early EEG and late EEG. \\
\hline Grigsby 1998 & Study did not make a comparison between EEG and no EEG or early EEG and late EEG. \\
\hline Gumus 2015 & Study did not make a comparison between EEG and no EEG or early EEG and late EEG. \\
\hline Heijbel 1980 & Study did not make a comparison between EEG and no EEG or early EEG and late EEG. \\
\hline Huang 2007 & Study did not make a comparison between EEG and no EEG or early EEG and late EEG. \\
\hline Kaminska 1999 & Study did not make a comparison between EEG and no EEG or early EEG and late EEG. \\
\hline Knudsen 1985 & Study did not make a comparison between EEG and no EEG or early EEG and late EEG. \\
\hline Mackintosh 1970 & Study did not make a comparison between EEG and no EEG or early EEG and late EEG. \\
\hline Mahmoudian 2004 & Study did not make a comparison between EEG and no EEG or early EEG and late EEG. \\
\hline Mamelle 1982 & Study did not make a comparison between EEG and no EEG or early EEG and late EEG. \\
\hline
\end{tabular}




\begin{tabular}{|c|c|}
\hline Study & Reason for exclusion \\
\hline Mamelle 1984 & Study did not make a comparison between EEG and no EEG or early EEG and late EEG. \\
\hline Natriashvili 2005 & Study did not make a comparison between EEG and no EEG or early EEG and late EEG. \\
\hline NCT01370044 & Study did not make a comparison between EEG and no EEG or early EEG and late EEG. \\
\hline NCT01694524 & Study did not make a comparison between EEG and no EEG or early EEG and late EEG. \\
\hline NCT01738841 & Study did not make a comparison between EEG and no EEG or early EEG and late EEG. \\
\hline NCT01884766 & Study did not make a comparison between EEG and no EEG or early EEG and late EEG. \\
\hline NCT01906619 & Study did not make a comparison between EEG and no EEG or early EEG and late EEG. \\
\hline NCT01931813 & Study did not make a comparison between EEG and no EEG or early EEG and late EEG. \\
\hline NCT01946594 & Study did not make a comparison between EEG and no EEG or early EEG and late EEG. \\
\hline NCT02374450 & Study did not make a comparison between EEG and no EEG or early EEG and late EEG. \\
\hline Novotny 2010 & Study did not make a comparison between EEG and no EEG or early EEG and late EEG. \\
\hline O'Brien 2008 & Study did not make a comparison between EEG and no EEG or early EEG and late EEG. \\
\hline Pavlidou 2006 & Study did not make a comparison between EEG and no EEG or early EEG and late EEG. \\
\hline Pina-Garza 2005 & Study did not make a comparison between EEG and no EEG or early EEG and late EEG. \\
\hline Reijs 2007 & Study did not make a comparison between EEG and no EEG or early EEG and late EEG. \\
\hline Rosati 2003 & Study did not make a comparison between EEG and no EEG or early EEG and late EEG. \\
\hline Rose 2005 & Study did not make a comparison between EEG and no EEG or early EEG and late EEG. \\
\hline Rosenfeld 2014 & Study did not make a comparison between EEG and no EEG or early EEG and late EEG. \\
\hline Rosman 1987 & Study did not make a comparison between EEG and no EEG or early EEG and late EEG. \\
\hline Strengell 2009 & Study did not make a comparison between EEG and no EEG or early EEG and late EEG. \\
\hline Tsuboi 1988 & Study did not make a comparison between EEG and no EEG or early EEG and late EEG. \\
\hline Vecchi 2016 & Study did not make a comparison between EEG and no EEG or early EEG and late EEG. \\
\hline
\end{tabular}

EEG: electroencephalograph.

\section{AP PEN DICES}

\section{Appendix 1. Search strategy}

\section{EEG for children with complex febrile seizures}

\section{Epilepsy Specialized Register}

\#1 MeSH DESCRIPTOR Seizures, Febrile Explode All 
\#2 (febrile seizure*) or (febrile convulsion*) or (pyrexial seizure*) or (pyrexial convulsion) or (fever seizure*) or (fever convulsion*) \#3 \#1 OR \#2

\#4 MeSH DESCRIPTOR Electroencephalography Explode All

\#5 electroencephalograph^ or EEG

\#6 \#4 OR \#5

\#7 \#3 AND \#6 AND INREGISTER AND >06/07/2015:CRSCREATED

\section{CENTRAL via Cochrane Register of Studies Online (CRSO)}

\#1 MESH DESCRIPTOR Seizures, Febrile EXPLODE ALL TREES

\#2 (febrile seizure ${ }^{\star}$ OR febrile convulsion* OR pyrexial seizure* OR pyrexial convulsion ${ }^{\star}$ OR fever seizure* OR fever convulsion ${ }^{\star}$ ):TI,AB,KY \#3 \#1 OR \#2

\#4 MESH DESCRIPTOR Electroencephalography EXPLODE ALL TREES

\#5 (electroencephalograph* OR EEG):TI,AB,KY

\#6 \#4 OR \#5

\#7 \#3 AND \#6

\#8 * NOT INMEDLINE AND 30/06/2015 TO 31/01/2017:DL

\#9 \#7 AND \#8

\#10 ("Conference Abstract"):PT AND INEMBASE

\#11 \#9 NOT \#10

\section{MEDLINE (Ovid)}

This strategy is based on the Cochrane Highly Sensitive Search Strategy for identifying randomized trials (Lefebvre 2011).

1. (randomized controlled trial or controlled clinical trial or pragmatic clinical trial).pt. or (randomi?ed or placebo or randomly).ab.

2. clinical trials as topic.sh.

3. trial.ti.

4. 1 or 2 or 3

5. exp animals/ not humans.sh.

6. 4 not 5

7. exp Seizures, Febrile/

8. febrile seizure ${ }^{\star}$.tw.

9. febrile convulsion ${ }^{\star}$. tw.

10. pyrexial seizure*.tw.

11. pyrexial convulsion ${ }^{\star} . t w$.

12. fever seizure*.tw.

13. fever convulsion*.tw.

14.7 or 8 or 9 or 10 or 11 or 12 or 13

15. exp Electroencephalography/

EEG for children with complex febrile seizures (Review) 
16. (electroencephalograph^ or EEG).tw.

\section{15 or 16}

18. 6 and 14 and 17

19. remove duplicates from 18

20. limit 19 to ed=20150706-20170123

\section{ClinicalTrials.gov}

"Febrile Seizures" and Children | Studies received on or after 07/06/2015

\section{Appendix 2. Eligibility assessment form}

Name of the review author:

Date:

Title of the study:

Study ID:

Name of the authors of the study:

Name of the journal with year of publication:

Questions:

\begin{tabular}{llllll}
\hline No. & Questions & Remark \\
\hline 1 & Is the study a randomised clinical trial or a quasi-experimental study? & Yes & No Unclear & & \\
\hline 2 & Did participants in the study have complex febrile seizures with first episode? & Yes & No Unclear \\
\hline 3 & $\begin{array}{l}\text { Is a comparison made of no EEG and EEG (early EEG, late EEG, or any time \& ear- } \\
\text { ly versus late EEG) among children having complex febrile seizures with first }\end{array}$ & Yes & No Unclear & & \\
\hline 4 & episode? & Did the study report better epileptic management or assess risk of occurrence? & Yes & No Unclear \\
\hline
\end{tabular}

Final decision: Include

Exclude

Unclear

Pending

Note:

1. Reasons for excluding the study:

2. In case study is labelled as "unclear" - Contact the authors date:

3. In case study is labelled as "pending" - Contact the authors date:

4. Response of the author: date: 
5. Opinion of Cochrane Epilepsy Group sought: date:

6. Opinion of Cochrane Epilepsy Group: date:

Final decision:

Appendix 3. Data extraction form

\section{Date}

\section{Name of the review author}

\section{Title of included study}

\section{Authors}

\section{Journal}

\section{Year of publication}

\section{Sponsor of the study}

\section{Conflict of Interest}

\section{Participants}

Inclusion criteria

Exclusion criteria

\begin{tabular}{l} 
Age range \\
\hline Ethnicity \\
\hline Any other comorbid condition \\
\hline Notes
\end{tabular}

\section{Intervention}

No EEG and EEG (early, late EEG, or any other time) (with exact details of days of seizure attack)

\section{Notes}

Outcome for no EEG or EEG (early EEG, late EEG, \& early versus late EEG or any other time)

\section{No EEG}

EEG (early, late, or any other time)

\footnotetext{
List of outcomes
}

\section{Notes}

\section{Brief description of methodology}


'Risk of bias' tool

Comment:

Judgement: Yes No Unclear

\section{Allocation concealment}

Quote:

Comment:

Judgement: Yes No Unclear

\section{Blinding of participants, personnel, and outcome asses- Quote:}

sors

Comment:

Judgement: Yes No Unclear

\section{Incomplete outcome data}

Quote: 


\section{Comment:}

Judgement: Yes No Unclear

\section{Selective outcome reporting}

Quote:

Comment:

Judgement: Yes No Unclear

Comment:

Judgement: Yes No Unclear

\section{Clinical trial registration details}

Registration no.:

Website link:

Access date:

Primary outcome:

Secondary outcome:

Any discrepancy with respect to outcome (compare with report):

Any other discrepancy:

Note:

1. Response of the author sought: date:

2. Response of the author: date:

3. Opinion of Cochrane Epilepsy Group sought: date:

4. Opinion of Cochrane Epilepsy Group: date:

Final comments:

\section{Appendix 4. 'Risk of bias' tool}




\begin{tabular}{|c|c|c|c|}
\hline No. & $\begin{array}{l}\text { Name of the } \\
\text { bias }\end{array}$ & Description & Domains in the 'Risk of bias' table \\
\hline 1 & $\begin{array}{l}\text { Selection } \\
\text { bias }\end{array}$ & $\begin{array}{l}\text { Systematic differences between baseline characteris- } \\
\text { tics of the groups that are being compared }\end{array}$ & $\begin{array}{l}\text { - Sequence generation } \\
\text { - Allocation concealment }\end{array}$ \\
\hline 2 & $\begin{array}{l}\text { Performance } \\
\text { bias }\end{array}$ & $\begin{array}{l}\text { Systematic differences between groups in the care that } \\
\text { is provided, or in exposure to factors other than the in- } \\
\text { terventions of interest }\end{array}$ & $\begin{array}{l}\text { Blinding of participants, } \\
\text { personnel, and outcome } \\
\text { assessors }\end{array}$ \\
\hline 3 & Attrition bias & $\begin{array}{l}\text { Systematic differences between groups in withdrawals } \\
\text { from study }\end{array}$ & $\begin{array}{l}\text { - Incomplete outcome data } \\
\text { - Blinding }\end{array}$ \\
\hline 4 & $\begin{array}{l}\text { Detection } \\
\text { bias }\end{array}$ & $\begin{array}{l}\text { Systematic differences between groups in how out- } \\
\text { comes are determined }\end{array}$ & $\begin{array}{l}\text { Blinding of participants, } \\
\text { personnel, and outcome } \\
\text { assessors }\end{array}$ \\
\hline 5 & $\begin{array}{l}\text { Reporting } \\
\text { bias }\end{array}$ & $\begin{array}{l}\text { Systematic differences between reported and unre- } \\
\text { ported findings }\end{array}$ & $\begin{array}{l}\text { Selective outcome } \\
\text { reporting }\end{array}$ \\
\hline
\end{tabular}

\section{Appendix 5. 'Summary of findings' table}

The GRADE approach describes levels of the quality of a body of evidence as follows.

\begin{tabular}{llc}
\hline No. & Underlying methodology quality & Rating \\
\hline 1 & Randomised trials or double-upgraded observational studies & High \\
\hline 2 & Downgraded randomised trials or upgraded observational studies & Moderate \\
\hline 3 & Double-downgraded randomised trials or observational studies & Low \\
\hline 4 & $\begin{array}{l}\text { Triple-downgraded randomised trials, downgraded observational } \\
\text { studies, or case series/case reports }\end{array}$ & Very low \\
\hline
\end{tabular}

The following factors would have reduced the quality of the evidence.

\begin{tabular}{lll}
\hline No. & Factor & Consequence \\
\hline
\end{tabular}


(Continued)

1

Limitations in study design or execution (risk of

1 or 2 levels

bias)

\begin{tabular}{llc}
\hline 2 & Inconsistency of results & 1 or 2 levels \\
\hline 3 & Indirectness of evidence & 1 or 2 levels \\
\hline 4 & Imprecision & 1 or 2 levels \\
\hline 5 & Publication bias & 1 or 2 levels \\
\hline
\end{tabular}

The following factors would have increased the quality of the evidence.

\begin{tabular}{lll}
\hline No. & Factor & Consequence \\
\hline 1 & Large magnitude of effect & 1 or 2 levels \\
\hline 2 & Dose-response gradient & 1 level \\
\hline
\end{tabular}

For example, had we found that the results were precise, we would have chosen 'no' in GRADEpro (GRADEpro 2014). If serious imprecision was present, we would have chosen no. 4 and downgraded by one level in GRADEpro. If very serious imprecision was present, we would have chosen 'very serious', which may have led to downgrading of the quality of the evidence for the particular outcome by two levels. We would have documented this in a footnote in the 'Summary of findings' table.

\section{Appendix 6. Summary of the results of the search}

The following table summarises the results of the searches for the review.

\begin{tabular}{|c|c|c|c|c|}
\hline Database & Date searched & Number of 'hits' & $\begin{array}{l}\text { Total } \\
\text { number } \\
\text { of hits af- } \\
\text { ter dupli- } \\
\text { cates re- } \\
\text { moved }\end{array}$ & $\begin{array}{l}\text { Total } \\
\text { number } \\
\text { of hits af- } \\
\text { ter irrel- } \\
\text { evant re- } \\
\text { ports re- } \\
\text { moved }\end{array}$ \\
\hline $\begin{array}{l}\text { Cochrane Epilepsy } \\
\text { Group Specialized Reg- } \\
\text { ister }\end{array}$ & $\begin{array}{l}18 \text { October 2012, } 17 \text { October 2013, } 6 \text { July } \\
2015\end{array}$ & 7 (2012), 0 (2013), 0 (2015) & 28 & 0 \\
\hline CENTRAL & $\begin{array}{l}18 \text { October 2012, } 17 \text { October 2013, } 6 \text { July } \\
2015\end{array}$ & 13 (2012), 0 (2013), 3 (2015) & & \\
\hline $\begin{array}{l}\text { MEDLINE (Ovid) } \\
1946 \text { onwards }\end{array}$ & $\begin{array}{l}18 \text { October 2012, } 17 \text { October 2013, } 6 \text { July } \\
2015\end{array}$ & 21 (2012), 0 (2013), 0 (2015) & & \\
\hline
\end{tabular}

EEG for children with complex febrile seizures (Review) 
(Continued)

\begin{tabular}{|c|c|c|}
\hline ClinicalTrials.gov & $\begin{array}{l}18 \text { October 2012, } 17 \text { October 2013, } 6 \text { July } \\
2015\end{array}$ & 3 (2012), 5 (2013), 1 (2015) \\
\hline
\end{tabular}

Revised search results in 2017 are as follows.

\begin{tabular}{|c|c|c|c|}
\hline & Date of search & New hits & $\begin{array}{l}\text { New hits after } 2 \\
\text { irrelevant hits } \\
\text { removed }\end{array}$ \\
\hline Cochrane Epilepsy Group Specialized Register & 23 January 2017 & 0 & 4 \\
\hline CENTRAL via Cochrane Register of Studies Online (CRSO) & 23 January 2017 & 4 & \\
\hline MEDLINE (Ovid) 1946- & 23 January 2017 & 2 & \\
\hline ClinicalTrials.gov & 23 January 2017 & 0 & \\
\hline Total & & 6 & \\
\hline
\end{tabular}

WHAT'S NEW

\begin{tabular}{lll}
\hline Date & Event & Description \\
\hline 23 January 2017 & $\begin{array}{l}\text { New citation required but conclusions } \\
\text { have not changed }\end{array}$ & Conclusions are unchanged. \\
\hline 23 January 2017 & New search has been performed & $\begin{array}{l}\text { Searches were updated on 23 January 2017; no new studies were } \\
\text { identified. }\end{array}$ \\
\hline
\end{tabular}

\section{H I S T O R Y}

Protocol first published: Issue 7, 2011

Review first published: Issue 1, 2014

\begin{tabular}{lll}
\hline Date & Event & Description \\
\hline 3 February 2016 & Amended & Copyedits made to the Plain language summary. \\
\hline 6 July 2015 & New search has been performed & Searches updated 6 July 2015. \\
\hline 6 July 2015 & $\begin{array}{l}\text { New citation required but conclusions } \\
\text { have not changed }\end{array}$ & No new relevant studies identified; conclusions are unchanged. \\
\hline
\end{tabular}

\section{CONTRIBUTIONS OF AUTHORS}

Develop search strategy: PBS, SJ with Information Specialist. 
Search for trials: PBS, SJ with Information Specialist.

Obtain copies of trials: PBS, SJ, and SE with Information Specialist.

Select trials to include: PBS, SJ, and SE.

Draft the final review: PBS, SJ, and SE.

\section{DECLARATIONS OF INTEREST}

Pankaj B Shah: None known.

Saji James: None known.

S Elayaraja: None known.

\section{SOURCES OF SUPPORT}

\section{Internal sources}

- No sources of support supplied

\section{External sources}

- National Institute for Health Research (NIHR), UK.

This review was supported by the National Institute for Health Research, via Cochrane Infrastructure funding to the Epilepsy Group. The views and opinions expressed therein are those of the authors and do not necessarily reflect those of the Systematic Reviews Programme, NIHR, National Health Service (NHS), or the Department of Health.

\section{DIFFERENCES BETWEEN PROTOCOLANDREVIEW}

We did not attempt the data collection analysis and 'Summary of findings' table, as no study met the inclusion criteria. We decided to describe the process of different aspects of data collection and analysis in the present review, as it will be updated regularly and the full protocol may not be easily accessible to all users of this evidence.

\section{INDEX TERMS}

\section{Medical Subject Headings (MeSH)}

*Electroencephalography; *Seizures, Febrile; Time Factors

\section{MeSH check words}

Child, Preschool; Humans 